\title{
The Effect of Teacher's Verbal Communication and Non-verbal Communication on Students' English Achievement
}

\author{
Sukris Sutiyatno \\ STMIK Bina Patria Magelang, Central-Java, Indonesia
}

\begin{abstract}
The research aimed to reveal the effects of verbal communication and non-verbal communication on students' English achievement of Informatics department of STMIK Bina Patria Magelang, Central JavaIndonesia. The research employed a quantitative approach with survey research. The data was collected by using questionnaire and score of final English test.The data was analyzed by using regression. The results of the research, verbal communication gives a significant positive effect on the students' English achievement. Non-verbal communication gives a significant positive effect on the students' English achievement. Both verbal and nonverbal communication together give a significant effect on the students' achievement. Based on the conclusion of research result which shows the significant role of verbal communication and nonverbal communication in teaching and learning process, teachers need to maintain and develop effective communication in order to successfully transmit learning materials to students. One alternative to developing it is with a combination of the use of verbal and nonverbal communication.
\end{abstract}

Index Terms - verbal communication, non-verbal communication, English achievement, regression

\section{INTRODUCTION}

Communication is an integral part of our lives. We communicate in different ways to express our thoughts, feelings, knowledge, skills, and ideas. It is normally assumed that communication is identified with speech and sounds but communication is, in fact, the communication of verbal and non-verbal transmission of knowledge. Communication is the basis of all human contact, which is central to human life.(Bunglowala \& Bunglowala, 2015, p. 371). Meanwhile, Richards \& Schmidt (2010) states that communication is the exchange of ideas, information. In an act of communication there is usually at least one speaker or sender, a communication message which is transmitted, and a person or person for whom this message is intended (the receiver) (p. 97).

The way teachers communicate to the students is one of the many factors that help determine effective teaching and how the students perceive the teachers' communication might affect their effective and cognitive learning and their feeling throughout the learning process. Verbal and nonverbal immediate behaviors on the part of the teacher enhance positive and effective instructional interaction, which has direct effects on the students' attitude towards the teacher and the course and the students' willingness to learn (Richmond \& McCroskey, 2005; Pogue \& AhYun, 2006 as cited by Ballester, 2013, p. 10)

Peng Hong $\mathrm{Li}$ (2011) states that classroom teaching, in essence, is an activity of communication between the tacher and students by means of information transmission. In other words, the teacher and students covey messages by both verbal and non-verbal cues in classroom teaching. As a result, teachers should be aware of non-verbal behaviors in the classroom (p. 506). In teaching context, verbal communication can be defined as relationship that can be achieved through speaking and conversation. Teachers should use the words carefully to be successful in teaching. Each word provokes a feeling in people, specific emotions, and distinct function. If the words are applied in proper place, it will affect the soul and body of audience immediately. Therefore, it is appropriate that the teacher avoids using negative words in dealing with the students, i.e. such words as "I can't, it's impossible, never, etc (Gorham, 1988, p.52 in Rasyid 2013, p. 421).

Establishing a good communication between students and their teacher introduces successful steps for both learning and teaching process. Communication is more than words, and it is important for teachers to understand the nonverbal messages they are sending and receiving in classroom (Caswell, 1993; Miller, 2005 cited by Barmaki 2014, p. 441). Nonverbal messages include facial expressions, eye contact or lack of eye contact, proximity, and closeness, hand gestures, and body language (Miller, 2005 in Barmaki, 2014, p. 441).

Mostly teachers are unconsciously using their body parts and give gestures. They said that after along practice in the field of teaching it is impossible to control their styles, body movement (Haneef, 2014, p. 515). Meanwhile, Chaudhry $\&$ Arif (2012) states that nonverbal communication is the unspoken communication that goes on in every face to face encounter with another human being. It tells us their feelings towards us and how well are our words being received. (p. $56)$. 
In the foreign language classroom, compliance between verbal and nonverbal signals is one of the conditions for successful communication of teaching learning process. When having knowledge of verbal and nonverbal communication principles, teachers can teach and communicate better with the students. Teacher's emotional behavior and emphaty, their ability to show understanding for their students' feelings and actions, plays a very great role in making the teaching learning process more comfortable and successful. The problem is that not all teachers are able to synergize both verbal and nonverbal communication in teaching English Foreign Language (EFL).

\section{LITERATURE REVIEW}

People communicate in many different ways, one of the most important ways, of course, is through language (verbal communication). For a long time, only language occurs to us immediately when we discuss human communication, while nonverbal communication is neglected to large extent. In fact, nonverbal communication plays a very important role in teaching learning process (Bunglowala \& Bunglowala, 2015, p. 371). On the basis of the medium, communication had been divided into verbal communication and non verbal communication. Verbal communication involves the use of the language whereas the nonverbal communication is essentially based on the use of expressions, gestures, action etc. Both the forms of the communication are extremely important for complete transfer/understanding of the content yet when it comes to the teaching learning process, verbal communication plays a much more vital role in transfer of knowledge (Rawat, 2016, p.3059).

In the selection of words, the intended concept must be exactly in the words of the educator. It is appropriate to use clear, concise, polite, correct and rich expression in oral communication with the audience to transmit the speaker's intention to the audience properly (Najafi, 2013). Verbal skills are generally divided into four parts; listening, speaking, reading and writing. Among these skills, speaking has the bigger degree of importance and usefulness and has more decisive impact on oral communication with the audience (Khabaz, 2013).

Expression of words vividly and eloquently by the teacher causes the students to listen with dignity and willingness, sum up the facts, and think to solve the problem and supply the teacher's comment without any tensions or boredom. But using biased phrases often raises a sense of stubbornness and humiliation in the trainee, puts them out the cycle of learning and deep understanding of scientific content completely, and leaves irreparable psychological effects on the students (Mortazavi, 2013).

Chaudhry \& Arif (2012) state that verbal communication itself does not create that impact upon students' mind and hearts as does non-verbal communication that complements the verbalmessage. Same verbal message may create opposite meaning and interpretation by students, the way the message is communicated through the medium of nonverbal communication (p. 57).

A successful educator in the field of teaching should be aware of the power of words and its impact on the audience and avoid using words habitually without thinking. Also, ordering is one of the conflicts which leads to failure in human interaction. The teacher should express his opinion with proper words and within the defined framework for his comments to be effective penetrating. Therefore, the teacher as the sender of message, should first determine the framework of his message and then express his expectation of the students frankly with appropriate tone and words (Gholipour, 2007).

Haneef, et all (2014) states that more often non-verbal communication occur unconsciously. People are not aware of the fact that besides their verbal communication the nonverbal gestures also transmit a potent message. The body language, eye contact, physical appearance, and tone of voice provide meaningful information to the audience. Nonverbal communication is deemed much reliable and effective in comparison to verbal communication as it gives additional support to the verbal communication (p. 513).

Studies on non verbal communication have generally focused on the teaching mehods in the classroom which may be used in teaching any subject. Learners have not paid serious attention to the unique situation in English class. Foreign language teachers who intentionally control their movements and position enjoy a delicate but effective power.During pattern drills, they can increase observably by tempo of the class, while decreasing teacher talk at the same time. Language teachers can use body language such as gestures to signal and instigate changes in the class atmosphere and thus further their instructional goals, throughout a class period encompassing such as various activities as conversation and choral repetition (Qi Pan, 2014, p.2627).

Educators, psychologists, anthropologist and sociologists define body language or nonverbal communication as communication without words. It includes overt behaviors such as facial expressions, eye contact, touching and tone of voice. It can also less obvious, however, as through dress, postures and spatial distance. The most effective communication occurs when verbal and nonverbal messages are in sync, creating communication synergy (Ali, 2011, p.1097)

Negi (2009) states that By function of non-verbal communication what is meant is the message that NVC cues convey. Non-verbal behaviors occur simultaneously with the verbal message and they substitute, complement, regulate and contradict the verbal message. Substitution of non-verbal message occurs when a non-verbal cue is used instead of verbal one. For example, a head nod to indicate 'yes', pat on shoulder to show 'intimacy' and so on. Non-verbal behaviors also compliment, expand or modify the verbal message. For example, a teacher looking confident while delivering the lecture in the class enhances the quality of teaching. Non verbal message regulate the conversational Aow 
as well. For example, gestures, head movements and many other behaviors indicate how the interaction should progress (p.102).

\section{RESEARCH METHOD}

The research employed a quantitative approach with survey research. The population of this research was the second year students of Informatics department of STMIK Bina Patria Magelang which consisted of 76 students and all the members of population were used as the research respondent. The data of verbal communication and non-verbal communication were collected by using questionnaire, then the data of English achievement used the final score of English test. The data was analysed by using regression. Field (2000) states in regression analysis we fit a predictive model to our data and use that model to predict values of the dependent variable (DV) from one or more independent variables (IVs) (p. 103).

\section{RESUlts AND DisCUSSION}

\section{A. Description of the Research Data}

\section{Verbal Communication}

Measurement of verbal communication (25 questions) gets results: Scale 4 (often) is the most predominant answer given by respondents, reaching $71.0 \%$; then scale 3 (Medium) 18,68\% and 5 (Very Often) 10,32\%.

Interview score is evaluated on an interval developed by Sturges (Kothari, 2004, p. 125) shows that $23.68 \%$ of respondents are in the 95 to 97 of interval range, $26.32 \%$ of respondents are in the range of 98 to 100 . Other respondents are relatively even at other intervals of about $13 \%-15 \%$, except on the lowest and highest intervals.

Descriptions of the tendency of the use of verbal communication in communication teaching process are interpreted in five categories according to the scale of the answers used, namely: Very Low, Low, Medium, High, and Very High table 1. The interval width for categorization is determined in the following way (Richards, 2010, p. 30).

$\mathrm{k}=\left(\mathrm{Max}_{\text {hip }}-\mathrm{Min}_{\text {hip }}\right) / 5$

Whereas:

$\mathrm{k}$ : interval

$\operatorname{Max}_{\text {hip }}$ : highest hypothesis score

$\operatorname{Min}_{\text {hip }}$ : lowest hypothesis score

TABLE 1.

TENDENCY OF VERBAL COMUNICATION

\begin{tabular}{|l|l|l|}
\hline No & Categorization & Interval \\
\hline 1 & Very Low & $25-45$ \\
\hline 2 & Low & $>45-65$ \\
\hline 3 & Enough & $>65-85$ \\
\hline 4 & High & $>85-105$ \\
\hline 5 & Very High & $>105-125$ \\
\hline
\end{tabular}

Descriptive statistical calculation results show that the lowest empirical scale $=92$, the highest $=104$ and average $=$ 97.908: High category, implies that students use verbal language in communicating.

TABLE 2.

DESCRIPTIVEVERBAL COMUNICATION

\begin{tabular}{|c|c|c|}
\hline Parameters & Score The Empirical & Description \\
\hline Mean & 97.908 & \multirow{5}{*}{$\begin{array}{l}\text { 1. Number of questions: } 25 \text {; Scale: } 1-5 \\
\text { 2. Measurement of the range of hypotheses: } 25-125 \\
\text { 3. Categorization: High }\end{array}$} \\
\hline Std. Deviation & 2.62 & \\
\hline Minimum & 92 & \\
\hline Maximum & 104 & \\
\hline Mean & 97.908 & \\
\hline
\end{tabular}

The individual tendency characteristics shows that all students are categorized as high table 3. It implies that all students use verbal language in communicating. 
TABLE 3.

TENDENCY OF VERBAL COMUNICATION

\begin{tabular}{|l|l|l|l|}
\hline No & Categorization & Frequency & Percentage \\
\hline 1 & Very Low & 0 & 0 \\
\hline 2 & Low & 0 & 0 \\
\hline 3 & Enough & 0 & 0 \\
\hline 4 & High & 76 & 100.00 \\
\hline 5 & Very High & 0 & 0 \\
\hline & Total & 76 & 100.00 \\
\hline
\end{tabular}

\section{Nonverbal communication}

Nonverbal communication is measured through a questionnaire instrument consisting of 32 items with an answer scale of 1-5. The answer of scale 4 (Often) is mostly given by respondents, reaching 76.6\%; then scale 3 (Medium) 14.39 and 5 (Very Often) $8.88 \%$.

The response scans were reviewed on an interval developed by Sturges (Kothari, 2004, p.125) indicate, as many as $57.89 \%$ of respondents in the interval range of $122-130$. These intervals include the upper range that interprets the intention quite high. Other respondents were $\pm 20 \%$ in intervals below, and as much as $\pm 4 \%$ above.

Descriptions of the tendency of nonverbal communication to communicate are interpreted in five categories according to the scale of the answers used: Very Low, Low, Medium, High, and Very High table 4. The interval width for categorization is determined in the following manner (Richard, 2010, p.30):

$\mathrm{k}=\left(\mathrm{Max}_{\text {hip }}-\mathrm{Min}_{\text {hip }}\right) / 5$

Whereas:

$\mathrm{k}$ : interval

$\operatorname{Max}_{\text {hip }}$ : highest hypothesis score

Min $_{\text {hip }}$ : lowest hypothesis score

TABLE 4.

CATEGORIZATION OF NON VERBAL SCORE

\begin{tabular}{|l|l|l|}
\hline No & Categorization & Interval \\
\hline 1 & Very Low & $32.0-57.6$ \\
\hline 2 & Low & $>57.6-83.2$ \\
\hline 3 & Enough & $>832-108.8$ \\
\hline 4 & High & $>108.8-134.4$ \\
\hline 5 & Very High & $>134.4-160.0$ \\
\hline
\end{tabular}

The results of descriptive statistic calculation acquire the lowest empirical score of 96 , highest $=143$ and average $=$ 126.158: High category. Interpreting students in general often use nonverbal language in communicating.

TABLE 5.

DESCRIPTIVE OF NON VERBAL SCORE

\begin{tabular}{|c|c|c|}
\hline Parameters & Score the Empirical & Description \\
\hline Mean & 126.158 & \multirow{5}{*}{$\begin{array}{l}\text { 1. Number of questions: } 32 ; \text { Scale: } 1-5 \\
\text { 2. Measurement of the range hypotheses: } 32-160 \\
\text { 3. Categorization: High }\end{array}$} \\
\hline Std. Deviation & 6.33 & \\
\hline Minimum & 96 & \\
\hline Maximum & 143 & \\
\hline Mean & 126.1578947 & \\
\hline
\end{tabular}

The individual tendency characteristics: as many as $93.42 \%$ of the students are in high category, $5.26 \%$ are in very high, and $1.32 \%$ are in moderate. It implies that all students tend to use nonverbal language in communicating, over $93 \%$ of students are in high category, and more than $5 \%$ of students are in very high category (table 6).

TABLE 6.

TENDENCY OF NONVERBAL COMMUNICATION

\begin{tabular}{|l|l|l|l|}
\hline No & Categorization & Frequency & Percentage \\
\hline 1 & Very Low & 0 & 0 \\
\hline 2 & Low & 0 & 0 \\
\hline 3 & Enough & 1 & 1.32 \\
\hline 3 & High & 71 & 93.42 \\
\hline 4 & Very High & 4 & 5.26 \\
\hline \multicolumn{3}{|c|}{ Source: Primary data Processing } \\
\hline
\end{tabular}

\section{English Achievement}

The result of English achievement measurement acquires the lowest value $=60$, the highest $=92$ and average $=$ 77.132. A mean of more than 75 indicates that students has reached the established mastery level, which is 75 . 
TABLE 7.

DESCRIPTIVE ENGLISH LANGUAGE ACHIEVEMENT

\begin{tabular}{|l|l|l|}
\hline Parameters & Score The Empirical & Description \\
\hline Mean & 77.132 & \\
\cline { 1 - 2 } Std. Deviation & 6.70 & Achievement average reaching mastery level*. \\
\cline { 1 - 2 } Minimum & 60 & \\
\cline { 1 - 2 } Maximum & 92 & \\
\hline Mean & 77.132 & Source: Primary data Processing \\
\hline
\end{tabular}

The achievement of individual mastery level indicates that all the students are in the high category. This implies that all students use verbal language in communicating.

TABLE 8.

ENGLISH LANGUAGE ACHIEVEMENT

\begin{tabular}{|l|l|l|l|}
\hline ENGLISH LANGUAGE ACHIEVEMENT \\
\hline No & Categorization & Frequency & Percentage \\
\hline 1 & Below mastery level & 24 & 31.58 \\
\hline 2 & Reached mastery level & 52 & 68.42 \\
\hline & Total Source: Primary data Processing & 100.0 \\
\hline
\end{tabular}

\section{B. Regression Analysis}

\section{Assumption Test}

\section{a. Normality Test}

Normally distributed data assumption is confirmed by Kolmogorov Smirnov test. The test results obtained Coefficient Kolmogorov Smirnov $=0.948$ with $\mathrm{p}=0.330$ on the verbal communication variable Kolmogorov Smirnov coefficient $=1.016$ with probability $(\mathrm{p})=0.253$ on the nonverbal communication variable; Coefficient Kolmogorov Smirnov $=0.872$ with $\mathrm{p}=0.433$ on the English achievement variable. Acquisition $\mathrm{p}>0.05$ denotes normal distributed data (Sheskin, 2004, p.239). Thus the plan for the use of multiple regression parametric statistics can proceed.

TABLE 9.

NORMALITY TEST RESULTS

\begin{tabular}{|l|l|l|l|}
\hline No & Variable & Coefficient k-s & $\mathrm{P}$ \\
\hline 1 & Verbal Communication & 0.948 & 0.330 \\
\hline 2 & Nonverbal Comunication & 1.016 & 0.253 \\
\hline 3 & English language achievement & 0.872 & 0.433 \\
\hline
\end{tabular}

Source: Primary data Processing

\section{b. Linearity Test}

Independent data assumption of linear to dependent variable pattern was confirmed with $\mathrm{F}$ test. Result of the test reveals that $\mathrm{F}$-statistic $=0.338$ with $\mathrm{p}=0.974$ on variable verbal communication and $\mathrm{F}$-statistic $=1.668$ and $\mathrm{p}$ value $=0.068$ on nonverbal communication variable. $\mathrm{p}>0.05$ shows independent data is linear to dependent variable pattern.

TABLE 10.

LINEARITY TEST RESULT

\begin{tabular}{|l|l|l|l|}
\hline No & Independent & $\mathrm{F}_{\text {test }}$ & $\mathrm{P}$ \\
\hline 1 & Verbal Communication & 0.338 & 0.974 \\
\hline 2 & Nonverbal Communication & 1.668 & 0.068 \\
\hline
\end{tabular}

\section{Regression test}

Effect of verbal and nonverbal communication variables simultaneously on achievement in English was evaluated using multiple-regression statistic. Effect of both independent variables is explained by determination parameters, while effect of each independent variable partially is explained by regression coefficient $(\beta)$ table 11.

TABLE 11.

TEST Result OF MultiPle REgRession

\begin{tabular}{|l|l|l|l|l|}
\hline \multirow{2}{*}{ Variable } & \multicolumn{2}{l|}{ Coef. Regression } & \multirow{2}{*}{} & \multirow{2}{*}{ T } \\
\cline { 2 - 3 } Constant & $\mathrm{B}$ & $\mathrm{B}$ stan & $\mathrm{T}_{\text {-test }}$ & $\mathrm{P}$ \\
\hline $\mathrm{X} 1-$ Verbal Communication & -78.295 & 0.332 & -3.461 & $<0.0001$ \\
\hline $\mathrm{X} 2-$ Nonverbal Communication & 0.848 & 0.542 & 3.856 & $<0.0001$ \\
\hline Multiple Correlation $(\mathrm{R})$ & 0.574 & & 6.251 & $<0,0001$ \\
\hline Determination Coefficient $\left(\mathrm{R}^{2}\right)$ & 0.686 & & \\
\hline$[1] \quad \mathrm{F}_{\text {-test }}$ & 0.470 & & $<0.0001$ \\
\hline
\end{tabular}


Individual effect of independent variable explains contribution of one variable independent over dependent variable along with the other variables. The effect of verbal communication on achievement in English along with nonverbal communication and effect of nonverbal communication on achievement in English along with verbal communication. Based on the table, regression equation explaining individually effect of independent variable is $\mathrm{Y}=-78.295+0.574 \mathrm{X} 1$ $+0.848 \mathrm{X} 2$

The equation explains

1) Constant

Constant explains score of achievement in English when factors affecting it are omitted. Negative constant indicates that students decrease their achievement when verbal and nonverbal communication are not conducted.

2) Effect of Verbal Communication

Verbal communication in regression function together with non verbal communication has positive regression coefficient of 0.848 explains that increasing in verbal communication can increase achievement in English and likewise decreasing in verbal communication can decrease achievement in English ceteris paribus for increasing in one unit of verbal communication can increase achievement in English of 0.848 unit. Significance of individual effect was evaluated by $\mathrm{t}$ test. Table 11 indicates that $\mathrm{t}$ statistic for verbal communication is 3.856 with $\mathrm{p}<0.05$ indicates significant.

3) Effect of Non Verbal Communication

Non verbal communication in the regression function with verbal communication has coefficient of 0.574 explains that non verbal communication can influence achievement in English at 0.574 ceteris paribus. Positive score indicates that increasing in non verbal communication can increase achievement in English and decreasing in non verbal communication has impact on decreasing in achievement in English. Significance partial effect of non verbal communication was evaluated through $\mathrm{t}$ test. The table 11 indicates that $\mathrm{t}$-statistic of non verbal communication is 6.251 with $\mathrm{p}<0.05$ indicates significant.

b. Simultaneous Effect

Determination coefficient $\left(\mathrm{R}^{2}\right)$ indicates contribution of all independent variables simultaneously on dependent variable. The coefficient of 0.470 explains that verbal communication and non verbal communication contribute $47 \%$ to achievement in English, while other unstudied variables contribute 53\%. Significance of determination is evaluated with $\mathrm{F}$ test; result of $\mathrm{F}$ statistic $=32.384$ with $\mathrm{p} \leq 0.05$ indicates significant result.

3. Hypothesis Test

The First hypothesis states that verbal communication influences significantly on achievement in English. Multiple regression test indicates regression coefficient $\beta=0.848$ with $\mathrm{p}<0.05$ on verbal communication. $\mathrm{P}<0.05$ indicates significant result. So, it implies that empirical fact supports the first hypothesis.

The second hypothesis is that non verbal communication influences significantly achievement in English. Multiple regression test indicates regression coefficient $\beta=0.574$ with $\mathrm{p}<0.05$ on non verbal communication. $\mathrm{P}<0.05$ indicates significant result. So, it implies that empirical fact supports the second hypothesis.

The third hypothesis states verbal and nonverbal communication affect simultaneously on achievement in English. Result of regression test shows determination coefficient of 0.470 with $\mathrm{p}<0.05$. Result of $\mathrm{p}<0.05$ indicates significant result and it implies that empirical facts support the third hypothesis.

\section{Discussion}

Verbal and nonverbal communication are revealed to give significant effects on the learning English achievement of second year students of Informatics of STMIK Bina Patria Magelang. Its contribution can be explained statistically by $47 \%$, where verbal communication contributes higher $(\beta=0.848)$ than nonverbal $(\beta=0.574)$.

The findings of this research can be utilized to strengthen the results of previous research on communication in teaching and learning process, which has contributed positively to the learning achievement. Behjat F. (2014), nonverbal communication using facial expressions and eye contact play a significant role in language learning; Surkamp (2014), The use of verbal and nonverbal communication by teachers have a positive impact on language learning; Panjaitan et al (2017), The use of verbal and nonverbal communication helps students understand the material presented by the teacher.

Verbal teacher immediacy refers to the verbal messages that show empathy, openness, kindness, reward, praise, feeling of inclusiveness, humor personal knowledge and willingness to engage students in communication, among others. Inevitably linked to nonverbal immediacy behaviours, verbal immediacy has been associated with increase cognitive and affective learning and with increased motivation (Cristophel, 1990, Rodriguez, Plax \& Kearny, 1996). Consistency of the results of some research related to the positive role of communication is factual in accordance with the fact that the way of human communication is a unique ability that plays a role in human existence as a social being (Birchenall, 2016).

The teacher's timely use of nonverbal communication can be done through a simple greeting with students which is the best way to start the class, and is of course impossible without nonverbal language. In the field of teaching, certainly one of the main characteristics of good teacher is good communication skill in classroom. Through the use of nonverbal language, teachers draw the students' attention to more understanding and motivate the students and even bring excitement to the bored students. The students unconsciously receive nonverbal signals sent from the teacher; they 
immediately notice that the one standing before them is teaching by all his/her will or is constantly waiting for the class to be ended (Najafi, 2013).

Surkamp (2014) states that non-verbal behavior is also relevant as communicative strategy. Nonverbal communication can help the learners both to understand the foreign language and to express themselves in it. Lacking knowledge of vocabulary or not being able to produce speech can be compensated for by the decoding of nonverbal signals or by transmission of part of the communicative intention to the gesture modality. Similarly, the emotive function of nonverbal behaviour can give students valuable information about the emotions and the intentions of their conversation partner in linguistic emergencies. Making use of the phatic function of nonverbal communication, in addition, can be a strategy for speakers to use their own facial expression and/or gestures in order to give feedback to their conversation partner concerning their reaction to the perceived communicative process or, inversely, to interpret whether the communication is successful or not by decoding their conversation partner's non-verbal behaviour ( $\mathrm{p} .16$ ).

Bunglowala \& Bunglowala (2015, p.371) research has indicated that teachers are required to learn to use non-verbal communication to improve classroom teaching. In addition, Salimi (2014) found that the students' attitude about English vocabulary and their comprehension with non-verbal communication indicated that they had a positive attitude toward the use of non-verbal communication in learning the second language.

In addition, Peng hon-li (2011) states as the teacher is put at the dominating role in classroom teaching, the nonverbal signals he/she uses in the classroom have great influence on the teaching effect. As a result, college English teachers should not only be aware of the role played by nonverbal communication means in classroom teaching, but also should set a good example for students in the application of non-verbal communication means (p. 506). Then, Edwards \& Edwards (2001) revealed that a high correlation exists between verbal and nonverbal immediacy but nonverbal immediacy may exist independently of verbal messages and this is why it is often given more importance in classroom research.

Haneef, et al states that body language or non-verbal communications have deep linked with communication. In the field of teaching where the communication skills play more important role then important of the body acting become more important. Teachers believe without effective body language it is impossible to communicate the class (p. 515).

Azam \& Kingdon (2014) reported in a study that teachers matter a great deal as far as achievement of students is concerned. Apart from the basic knowledge, the effective communication plays a major role in motivating the students, knowing their aspiration and the problems that they may have. Though, both the verbal and nonverbal communication play a role, yet an effective verbal communication helps in building a strong teacher student relationship which act as platform for the strong cognitive development. Easy and effective verbal communication helps the teacher to get an insight into the students' thought, ideas and opinion whereas the students get the knowledge of the teacher's expectation, knowledge and skills.

\section{CONClusions AND SugGestions}

\section{A. Conclusions}

The result of the regression test shows that the effect of independent variable to dependent variables individually and simultaneously. Based on these findings, it is concluded;

1. Verbal communication gives a significant positive effect on the English achievement of second year students of informatics department of STMIK Bina Patria Magelang .. $(\beta=0,848, p=<0,05)$.

2. Nonverbal communication gives a significant positive effect on the English achievement of second year students of informatics department of STMIK Bina Patria Magelang $(\beta=0,574, p<0,05)$.

3. Verbal and nonverbal communication together give a significant effect on the English achievement of second year students of informatics department of STMIK Bina Patria Magelang. $\left(\mathrm{R}^{2}=0.470\right.$, F-hit $\left.=32.364, \mathrm{p}<0.05\right)$

\section{B. Suggestions}

The above conclusion shows the significant role of verbal communication and non-verbal communication in teaching and learning process. Teachers need to maintain and develop effective communication in order to teach the students effectively. Teachers can use combination of verbal communication and non-verbal communication as teaching technique with the objective to create interest amongst the students and hopefully students' English achievement will increase.

\section{REFERENCES}

[1] Ali, S.A.M. (2011). The use of non-verbal communication in the classroom. $1^{\text {st }}$ International Conference on Foreign Language Teaching and Applied Linguistics 1096-1099, May 5-7, 2011 Sarajevo.

[2] Azam, M. \& Kingdon, G. (2014). Assesing teacher quality in India. Discussion paper No. 8622.

[3] Ballester, E. P. (2015). Verbal and nonverbal teacher immediacy and foreign language anxiety in an EFL university course. Porta Linguarum 23, 9-24

[4] Barmaki, R. (2014). Nonverbal communication and teaching performance. Proceeding of the $7^{\text {th }}$ International Conference on Educational Data Mining (EDM), 441-443. 
[5] Behjat, F., Bayat, S. \& Kargar, A, A. (2014). An investigation of students' attitudes on teachers' nonverbal interaction in Iranian EFL classrooms. International Journal of Language and Linguistics 2 (6-1), 13-18.

[6] Birchenall B., L. (2016) Animal communication and human language. An overview: International Journal of Comparative Psychology 29.1, 1-26.

[7] Bunglowala, A \& Bunglowala, A. (2015). Non verbal communication: An integral part of teaching learning process. International Journal of Research in Advent Technology Special Issue $1^{\text {st }}$ International Conference on Advent Trends in Engineering. Science and Technology 8 Maret "ICATEST 2015", 371-375.

[8] Caswell, C. \& Neill, S. (193). Body language for competent teachers. Routledge.

[9] Chaudhry, N. A. \& Arif, M. (2012). Teachers' nonverbal behavior and its impact on student achievement. International Education Studies 5.4, 56-64.

[10] Christophel, D. M. (1990). "The relationship among teacher immediacy behaviours, student motivation, and learning", in Communication Education 37, 323-340.

[11] Edwards, A., \& Edwards, C. (2001). "The impact of instructor verbal and nonverbal immediacy on student perception of attractiveness and homophily". In Journal of Excellence in College Teaching 12.2, 5-17.

[12] Field, A. (2000). Discovering statistics using SPSS. London: SAGE Publications

[13] Gholipour, A. (2007). Pathology of teacher-student relationship from the perspective of teachers and secondary students in the city of Parsabad. Ardebil: Department of Education Ardebil.

[14] Gorham, J.(1988). The relationship between verbal intermediacy behaviors, student motivation, and learning. Communication educator 37, 40-53.

[15] Haneef, Faisal \& Zulfiqar. (2014). The role of non-verbal communication in teaching practice. Sci. Int. (Lahore) 26.1, 513-517.

[16] Khabaz, Z. (2013). The effect of nonverbal language on teaching. available from: http://hamshahrionline.ir (accessed 7/6/2017 11:03 AM).

[17] Kothari. (2004). Research methodology methods \& techniques. New Delhi: New Age International (P) Ltd., Publishers.

[18] Miller,P. W. (2005). Body language in the classroom. Techniques: Connecting Education and Careers 8, 28-30.

[19] Mortazavi M. (2013). Meta-analysis of communication patterns in math learning journal article. Journal of Educational Technology 9.2, 155-164. Persian.

[20] Najafi, T. \& Rahmanzade, A. (2013). The relationship between communication skills and educational effectiveness of teachers of girls in Valiasr Technical College in Tehran. Journal of media studies 8.4, 193-206. Persian.

[21] Negi, J, S. (2009). The Role of teachers' non-verbal communication in ELT classroom. Journal of NELTA 14.1-2, 101-110.

[22] Panjaitan T.P., Irma Suryani, Sri Wanasari, Syarifah Chairunisak. (2017). Interaction of verbal communication of the teacher from the Philippines in the teaching activity for nursery II students at the Singapore international school, Medan. International Journal Of Scientific \& Technology Research 6.7, 33-40.

[23] Peng Hong-li. (2011). Effects of non-verbal communication on college English classroom Teaching. US-China Foreign Language 9.8, 505-516.

[24] Pague, L. L. \& AhYun, K. (2006). "The effect of teacher nonverbal immediacy and credibility on student motivation and affective learning". In Communication Education 35, 43-55.

[25] Qi Pan (2014). Nonverbal teacher-student communication in the foreign language classroom. Theory and Practice in Language Studies 4.12, 2627-2632.

[26] Rasyid, M. A. (2013). Verbal and non-verbal immediacy in EFL classroom. ICOLE UNM 6-7 December 2013, 419-430

[27] Rawat, Ms. D. (2016). Importance of communication in teaching learning process. Scholarly Research Journal for Interdisciplinary Studies 4.4, 3058-3063.

[28] Richards, J. C. \& Schmidt, R. (eds). (2010). Longman dictionary of language teaching and applied linguistics. Harow, UK: Pearson Education Limited.

[29] Richmond, V. P. \& McCrosky, L.L. (2005). An introduction to communication in the classroom: The role of communication in teaching and learning. Boston: Pearson.

[30] Rodriguez, J. I., Plax, T.G. \& Kearny, P. (1996). "Clarifying the relationship between teacher nonverbal immediacy and student cognitive learning: Affective learning as the central causal mediator." In Communication Education 45, 293-305.

[31] Salimi, A. (2014). The attitude of EFL learners about English vocabulary and comprehension using non-verbal communication. Journal of Educational Technology 1, 1-9.

[32] Sheskin, D., J. (2004). Parametric and nonparametric statistical procedures. Chapman \& HalVCRC, US.

[33] Surkamp, C. (2014). Non-verbal communication: Why we need it in foreign language teaching and How we can foster it with drama activities. Scenario 2, 12-27.

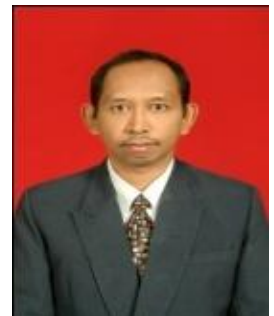

Sukris Sutiyatno was born in Solo, Central-Java Indonesia. He graduated his S1 English Department of Muhammadiyah University of Surakarta, S2 Master of Management of STIE Mitra Yogyakarta, S2 Applied Linguistics of Yogyakarta State University and S3 Technological Vocational Education of Yogyakarta State University, he was visiting scholar at Birmingham City University (BCU) UK 2011. He is lecturer at STMIK Bina Patria Magelang, Central-Java, Indonesia.

His areas of interest are Linguistics, Management and Educational Management. He has published four books: 1. Kepemimpinan Pembelajaran dan Manajemen Kepuasan Siswa, 2. English for Information Technology, 3. English for Information Systems and Business, 4. Metodologi Penelitian.

Dr. Sutiyatno is head of STMIK Bina Patria Magelang, Board of Advisors of Indonesia Educationist Association (IEA) Magelang and Secretary of APTISI Region IV Central Java, Indonesia. 